\title{
Initiatives to Build Capacity in the Area of Food Safety and Analysis
}

\author{
Senthil Kumar Kurunthachalam \\ Analytical and Technology Scientist, Central Analytical Lab, Sadara Chemical Company, Jubail, Saudi Arabia
}

\section{Introduction}

Food Safety and Risk Analysis (FSRA) plays a vital role in terms of producing high grade food and products and to ensure safety and protection of public health. In addition, the food and product safety norms should be uniform at national and international standards which corresponding to well define scientific regulations. Consequently, the subject of FSRA is very important due to; Increased risks of food-borne illness; Adulteration of food and soft drinks (e.g., monosodium glutamate (MSG)); Food or its ingredients prepared, handled and packed in non-hygiene conditions (e.g., toxic vegetables and fruits in India); Pesticides, fertilizers and endocrine mimicking hormones (e.g., pesticides in soft drinks, bisphenol-A in canned food); Food packaging materials (e.g., migration of chemicals from packaging materials to food [1]); Increased globalized food supply which requires stringent food safety systems (e.g., food manufacturers should have Certificates of Analysis from their suppliers for the exportation); Presence of dioxins, veterinary drugs, heavy metals, microorganisms, residues, genetically modified and bio-active substances, allergens and animal proteins should be tested (Table 1); and Artificial egg, rice and other foods entry into the market (e.g., news on 11 Biggest Food Scandals That Will Shock You) and Bioterrorism through food. When considering all these above-mentioned factors, developing countries are "hotspots" as they are meagrely equipped to address the existing and emerging food safety issues. Some countries are lacking with the technical and financial resources, an effective institutional framework, trained manpower and sufficient information about the hazards and risks involved.

Despite steady progress to strengthen food safety issues has been achieved in some developed nations, with special emphasis on opportunities to reduce and prevent food-borne disease. However, unacceptable rates of food-borne illness still remain and new hazards continue to enter the food supply. Multiple news, grey literature and social media reported, flavouring agents used in confectionery are nothing but poly (dimethyl siloxane), acids, the "castoreum" the yellowish secretion from Beaver urine sac used also in confectionery and perfumes and several of other chemical intermediates. Chicken nuggets had tertiary butylhydroquinone (TBHQ) and ice cream has propylene glycol or ethylene glycol. Vanilla flavour is nothing but a petrochemical by producing an artificial vanillin from guaiacol or lignin. The manufacturer claims to use alleged toxic chemicals at Codex permitted levels? Therefore, artificial flavouring /colouring chemicals remains a mystery as these chemicals initiate detrimental effects on humans and brings a debate of future food scandal episodes.

Consequently, food safety and its linked discipline of a "risk analysis" being introduced with 1) risk assessment, 2) risk management

\begin{tabular}{|l|l|l|}
\hline Biological hazards & Chemical hazards & Physical hazards \\
\hline Infectious bacteria & $\begin{array}{l}\text { Chemical contaminants from } \\
\text { packaging }\end{array}$ & Allergens \\
\hline Toxin-producing organisms & Naturally occurring toxins & Metal, machine fillings \\
\hline Molds, fungi & Food additives & Hair, nails \\
\hline Parasites, actinomycetes & Pesticide residues & Glass/staples \\
\hline Pathogenic virus, norovirus & Veterinary drug residues & Jewelry \\
\hline Prions, algae & Environmental contaminants & Stones, plastic \\
\hline Biological terrorism & Food handling & Bone chips \\
\hline
\end{tabular}

Table 1: Important hazard list anticipated in food stuffs. and 3) risk communication (Figure 1). In general, the risk analysis approach is linked with negative health implications to humans from the hazards in the food chain. The Food and Agriculture Organization (FAO) and the World Health Organization (WHO) have played a predominant role in the developing food safety risk analysis since 1990s [2]. Because FSRA is not only serving the individual, but also helps to improve the economy of the country. Considering these facts in to a valuable advantage, in this editorial, the important aspect of initiating the capacity building of food safety and analysis by a fastdeveloping country like India has been highlighted. Because food safety is a serious public health concern in India holding $>1.2$ billion humans, despite Gross Domestic Product (GDP) has increased 4.5 times and per capita consumption has increased 3 times. India feeds geographically dispersed populations in which $15.2 \%$ people were malnourished and 3,000 children die every day (i.e., 1 of 4 children). All these events arise by the proliferation of illegal, dishonest, and bootleg suppliers and slipshod government policies. The results are detrimental to public health, particularly for vulnerable communities [3].

\section{Indian Stand on Food Safety}

In order to initiate and build capacity in the area of FSRA, Food Safety Standard Act should be strictly defined at national level (Table 2) which should be uniform to international standards. In India, Food Safety and Standards Authority of India (FSSAI) has been developed with Food Safety and Standards Act in 2006 [4]. Ministry of Health and Family Welfare, Government of India, is the administrative ministry for the implementation of FSSAI. Particularly, FSSAI has an authority to regulate the production, manufacture, storage, distribution, commercialize, import and export to ensure availability of safe and hygienic food for human consumption. Until last year, FSSAI standardized 380 food items from 16 categories [5]. However, $>12,000$ items are non-standardized but nearing finalization in harmonization with Codex Alimentarius. All the standardized food products are safe for commercialization and exportation. Nevertheless, food safety standards are not achieved up to international standards as several of Indian food, food products, cosmetics, pharmaceuticals and medicines declined abroad.

Food scandals have plagued India during the past several decades. The popular example of Nestle's Maggi noodles analysed by FSSAI contains MSG, lead and other chemical contaminants, those ultimately cause adverse health effects to humans. Tests in six countries, including USA, Canada, the UK and Singapore have determined the product to be safe for consumption. In a legal petition, the company argued that India's testing system is flawed, leading to inaccurate findings [6]. Another episode of pesticides in all types of Pepsi brands, Mountain

${ }^{*}$ Corresponding author: Senthil Kumar Kurunthachalam, Analytical and Technology Specialist, Central Analytical Lab, Sadara Chemical Company, Jubail, Saudi Arabia, Tel: +966503645432; E-mail: kuruntha@gmail.com

Received July 20, 2017; Accepted July 25, 2017; Published August 01, 2017

Citation: Kurunthachalam SK (2017) Initiatives to Build Capacity in the Area of Food Safety and Analysis. Med chem (Los Angeles) 7: e110. doi:10.4172/21610444.1000e110

Copyright: ( $) 2017$ Kurunthachalam SK. This is an open-access article distributed under the terms of the Creative Commons Attribution License, which permits unrestricted use, distribution, and reproduction in any medium, provided the original author and source are credited. 
Citation: Kurunthachalam SK (2017) Initiatives to Build Capacity in the Area of Food Safety and Analysis. Med chem (Los Angeles) 7: e110. doi:10.4172/2161-0444.1000e110

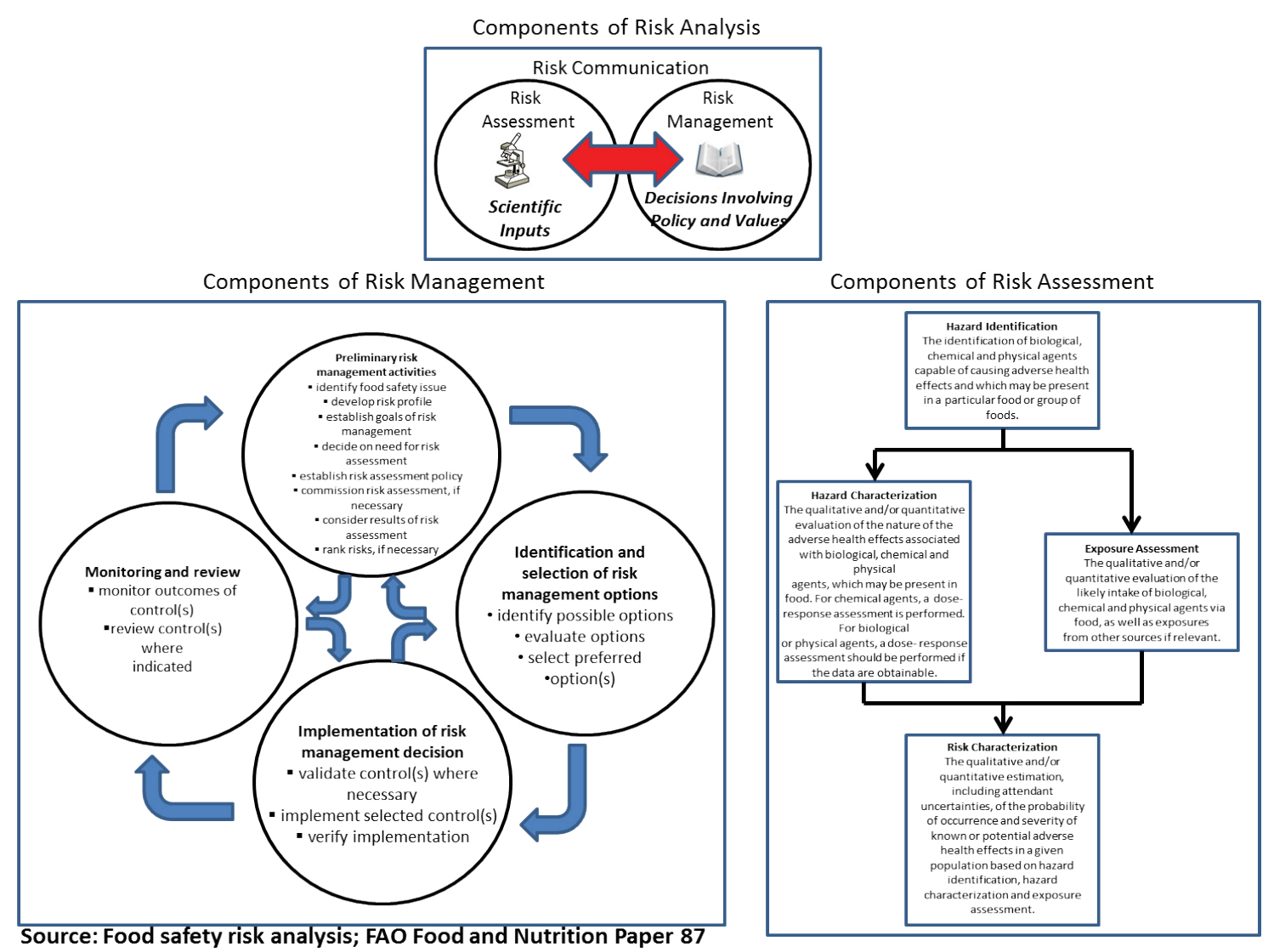

Figure 1: Important components of risk, analysis, management, a and assessment. Source: [4] Reference Food safety risk analysis a guide for national food safety authorities.

Food laws, policies, regulations and standards.

Institutions with clearly defined responsibilities for food control management and public health.

\section{Scientific capacity.}

Integrated management approach.

Inspection and certification.

Diagnostic and analytical laboratories.

Standard-setting.

Infrastructure and equipment.

Monitoring structures and capabilities.

Surveillance of human health problems related to food intake.

Capacity for emergency response.

Training.

Public information, education and communication.

Table 2: Major elements of food safety systems at the national level.

Dew, all brands of Mirinda, 7-Up, Coke, Fanta, Limca, Sprite, ThumsUp has been reported in India by Center for Science and Environment (CSE) in 2003. However, one reputed international testing lab in USA reported that water uses in aforesaid drinks in India are free of pesticides [7]. Other classical examples are plastic rice from north-east India, Illegal alcohol in West Bengal during 2011 and School Meal Poisoning in Bihar, during 2013. There are $>60$ food testing labs available in India with FSSAI notified and the National Accreditation Board for Testing and Calibration Laboratories (NABL) standard. However, food testing system and food testing labs needed to be upgraded to international standards.

\section{Establishing State-of-Art Accredited Food Testing Laboratories}

The value of international food trade reached 1.5 trillion US\$/year particularly, Indian food production and supply becoming increasingly globalized and therefore it is an urgent requirement to strengthen food safety systems. The Codex Alimentarius has been playing a key role internationally in the area of food standards, with its dual mandates of protecting the health of consumers and ensuring fair practices in the food trade. Particularly, the food safety group promotes the application of preventive food safety management systems by food business operators along the food chain in line with Codex guidelines and recommendations. Codex is aimed at:

1. Promoting the application of Good Hygienic Practices (GHP) at all stages of the food chains and the Hazard Analysis and Critical Control Point (HACCP) system as appropriate.

2. Promoting sustainable development of capacities and systems by national institutions (private and public) to enable delivery of technical assistance within the country.

3. Developing tools and training materials for adaptation and use in support of national training programmers with the aim to strengthen important value chains and develop sector-specific national codes of practice.

In addition, the department of food safety and zoonoses developed to encourage; 
1. Donor support for food safety as a priority in public health in developing countries.

2. Develop regional food safety strategies based on both the common elements outlined in the WHO food safety strategy and specific regional needs.

3. Enhance participation in Codex activities.

4. Field studies to estimate the burden of food-borne disease.

5. Risk assessment and monitoring of chemical and microbiological hazards.

6. Establishing networks of WHO collaborating Centres and other partners engaged in capacity building and provide technical assistance, such as the Global Food-borne Infections Network (GFN).

\section{Educational tools for food safety initiatives.}

Besides, food businesses meet their food safety and quality responsibilities by implementing quality assurance systems along the food production chain. These sets of controls may include Good Agricultural Practices (GAP), Good Manufacturing Practices (GMPs), GHPs and HACCP systems. Many businesses can face challenges, but in particular small-scale producers and traders in fast developing countries like India need support in planning and implementing food safety management programmers' in line with international requirements.

Contradictory results have been reported by the Indian food testing lab when compared to the food testing labs in the UK, USA (e.g., Maggi noodles and pesticides in Coke). This shows that prospect of India's food monitoring system is either underdeveloped or not capable of producing reliable food analysis data. India feeds $>1.25$ billion people and availability of food testing labs with inadequate analytical equipment, expertise and analytical chemists to monitor official food safety in the country is not sufficient. Assuming the Maggi product sold in India is the same as that sold around the world, there appears to be a breakdown in India's food safety monitoring system. For example, use of milk adulterants and the increase in genetically modified products could produce digestive/chronic health effects which needed to be analyse by specialists with sophisticated instruments. India's agricultural products face import restrictions in the UK and other parts of the world due to the ostensibly lax regulations and enforcement. The FSRA in India has major threat, particularly among $>475$ Indian cities, water quality, sanitation and waste management are poorly maintained which reflected highest rates of child deaths with diarrhoea. Besides, adulteration of food is very common in India [8-10]. Some general adulterated foods are milk and milk products, atta, edible oils, cereals, condiments, pulses, coffee, tea, confectionery, baking powder, nonalcoholic beverages, vinegar, besan and curry powder. Overall, India should establish the state-of-the-art food testing labs covering the entire country with enough analytical technology and specialists.

\section{Risk Assessment Studies of Important Food Hazards in Recommending Standards to Meet Emerging Challenges}

A food safety risk analysis is essential not only to produce or manufacture high quality goods and products to ensure safety and protect public health, but also to comply with international and national standards and market regulations. India could adopt the Centre for Food Safety (CFS) risk analysis framework which is based on international food safety standards. As indicated in the introduction, risk analysis comprises, risk assessment, risk management and risk communication (Figure 1). Risk assessment denotes the scientific basis for control actions. In this instance, risk assessment consists of four components:
1) Hazard identification,
2) Hazard characterisation,
3) Exposure assessment,
4) Risk characterisation.

Following all four components, hazards involved with food or food products are estimated and possible risk to the population is addressed, facilitating the formulation of appropriate risk management actions and risk communication messages to protect public health. From several decades during past, risk assessment, risk management and risk communication have been formalized and incorporated into a process known as risk analysis. The new approach enables information on hazards in food to be linked directly to data on the risk to human health, a process which was not considered in the past. Risk assessment studies also can be classified into:

1. Risk assessment of chemical agents in food,

2. Risk assessment of biological agents in food.

In both classification, the hazard identification, epidemiological study, animal studies, hazard characterisation, dose-response extrapolation, dose-scaling, genotoxic and non-genotoxic carcinogens, threshold and non-threshold approaches made, exposure assessments and risk characterisation should be covered. By providing a sciencebased approach to improve food safety decision-making processes, risk analysis contributes to a reduction in the incidence of food-borne disease and in continuous improvements in food safety [1].

\section{Development and Validation of Test Methods for Food Additives and Contaminant at Trace Levels}

There is a continuing need for reliable analytical methods for use in determining compliance with national regulations as well as international requirements in all areas of food quality and safety. In order to validate the test methods for food additives and contaminant at trace levels the lab must be eligible with the following criteria:

1) Laboratory contains ISO-17025 certification,

2) Capable of doing the analysis based on ISO approved methods,

3) Analysis begins immediately the samples arrive at lab, and the results are ready as of the testing protocol,

4) Laboratory should provide references,

5) Laboratory will handle the samples,

6) Laboratory allows audits,

7) Laboratory has sufficient specialist food analysts,

8) Laboratory will provide results as well as interpret results statistically,

9) Laboratory demonstrates a sense of urgency with samples,

10) Laboratory has experience with sample matrix,

11) Laboratory has the ability to suggest possibly more appropriate tests,

12) Cost of services.

There may be other requirements that could be part of the selection criteria, but these 12 are enough to identify the laboratories that are truly qualified to be trusted with client food sample testing. 
Citation: Kurunthachalam SK (2017) Initiatives to Build Capacity in the Area of Food Safety and Analysis. Med chem (Los Angeles) 7: e110. doi:10.4172/2161-0444.1000e110

Page 4 of 4

\section{Development of Rapid and Simple Food Adulteration Detection Kits}

On the global scale $>3.5$ million peoples per year die due to food poisoning. Frequent food scandal episodes in India prompted that implement of rapid and simple food adulteration detection kits with high precision required. Laboratories are an essential component with adequate facilities for physical, microbiological and chemical analyses. Besides the simple routine analysis, the laboratories should also equip with sophisticated instruments, apparatus and library facilities. Development of rapid, accurate, easy-to-use and affordable testing methods could urge food handlers and the public to actively screen for food contaminants and toxic chemicals instead of passively relying on monitoring by the government examination aided labs. The monitoring and surveillance system must cover all the different parts of the food supply chain, from the agricultural production, food processing and storage, to the import, export and consumption of food in order to provide a food chain transparency and risk management for the government and public.

In India, a majority of food poisoning occurs with pathogenic microbes followed by chemical additives. The fast-micro-scale extraction and purification method is able to provide a quick, easy, cheap, effective, rugged, and safe (QuEChERS) for various food sample microbial analyses [11]. This method still involves the use of sophisticated instruments such as gas and liquid chromatographymass spectrometry (GC and LC-MS). Therefore, if the lab has a facility of GC-MS and LC-MS; majority of microbial, chemical, amino acid, protein food adulterants can be identified in a short time span. Analytical instruments such as LC-MS, Matrix Assisted Laser Desorption Ionization- time of flight (MALTI-TOF) and GC-MS have been used to directly determine the presence of bacterial and fungal toxins. The most commonly used method to determine the presence of bacterial and fungal toxins is high performance liquid chromatography (HPLC) with ultraviolet visible (UV-Vis) or Fluorescence Detection (FD) in combination with clean-up by immuno-affinity column, which has the recovery of about $90 \%$ and Limit of Detection (LOD) nearly $0.05 \mu \mathrm{g} / \mathrm{kg}$. For instance, the use of rapid testing allows enterprises to identify and manage risks at an early stage by performing screening tests.

Furthermore, the current demand of rapid food contaminant detection requires a faster, onsite, and preferentially naked eye detection of food sample analysis. Recent rapid testing of food contaminant is able to shorten the total detection time to 1 day for microorganisms or $30 \mathrm{~min}$ for chemicals. Thus, expanding the scope of rapid testing on food safety system is a potential way to step forward. Very common food adulterants in India can be found in the report by FSSAI report [8]. India's spices reported to contain lead poison (neurotoxin) and therefore rapid screening of inductive coupled plasma-optical electron spectrometer or atomic emission spectroscopy or -mass spectrometry (ICP-OES or AES or MS) and Atomic Absorption Spectrometry (AAS) could yield an accurate result in 30-60 min. Similarly, inorganic contaminants such as anionic and cationic substances in drinking water and soft drink samples could be screened by ion chromatography (IC) analysis. On the whole, FSRA has been one of the very important precaution measures to protect humans in order to avoid excessive intake of unwanted pathogens and chemicals or otherwise we are the last human generation endanger ourselves by ingesting frequent fast food, candy/confectionery, soft drinks and ice cream which contain alleged artificial chemicals and dyes.

\section{References}

1. Senthil Kumar K (2013) Possible Adverse Implications of Chemical Migration from Food Pack Materials to Food in India. Hydrol Current Res 4: 3.

2. FAO and WHO (2005) Food Safety Risk Analysis - Part I. An Overview and Framework Manual - Provisional Edition, Rome, Italy. June 2005. Report, pp: $1-86$.

3. Biswas AK, Hartley K (2015) India's food safety crisis is indicative of bureaucratic failures. India and Food Safety, The Diplomat, September 08, 2015.

4. FAO and WHO (2006) Food safety risk analysis a guide for national food safety authorities. FAO Food and Nutrition Paper 87.

5. Arora S (2015) Food Regulations-What is the Current Scenario in India? Food quality and Safety. September 9, 2015.

6. Davidson L (2015) Maggi noodles scandal in India weighs on Nestle' sales. 16th October 2015, The Telegraph.

7. Patranobis S (2006) India Press Report Coke \& Pepsi Are Loaded with Pesticide Residues, Poison in your soft drink, says study, Hindustan Times, New Delhi, August 5.

8. FSSAI (2012) Food Safety Standards and Authority of India Report (3/8/2012)

9. Kumar S (2013) Indian Waters Past and Present. Hydrol Current Res S10: 001.

10. Kumar S (2014) Water Conservation and Sustainability: An Utmost Importance. Hydrol Current Res 5: e117.

11. Chiou J, Leung AHH, Lee HW, Wong WT (2015) Food Safety Special Issue: Rapid testing methods for food contaminants and toxicants. Journal of Integrative Agriculture. Advance Online Publication 2015. 